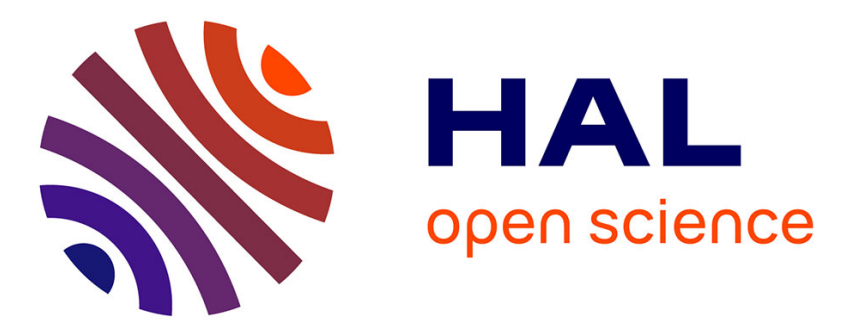

\title{
Biodegradable polyester thin films and coatings in the line of fire: the time of polyhydroxyalkanoate (PHA)?
}

Henri Vahabi, Elaheh Rohani Rad, Thibault Parpaite, Valérie Langlois, Mohammad Reza Saeb

\section{- To cite this version:}

Henri Vahabi, Elaheh Rohani Rad, Thibault Parpaite, Valérie Langlois, Mohammad Reza Saeb. Biodegradable polyester thin films and coatings in the line of fire: the time of polyhydroxyalkanoate (PHA)?. Progress in Organic Coatings, 2019, 133, pp.85-89. 10.1016/j.porgcoat.2019.04.044 . hal-02144575

\section{HAL Id: hal-02144575 \\ https://hal.univ-lorraine.fr/hal-02144575}

Submitted on 20 Nov 2020

HAL is a multi-disciplinary open access archive for the deposit and dissemination of scientific research documents, whether they are published or not. The documents may come from teaching and research institutions in France or abroad, or from public or private research centers.
L'archive ouverte pluridisciplinaire HAL, est destinée au dépôt et à la diffusion de documents scientifiques de niveau recherche, publiés ou non, émanant des établissements d'enseignement et de recherche français ou étrangers, des laboratoires publics ou privés.

\section{(1) (1) $\$$}

Distributed under a Creative Commons Attribution - NonCommercial - NoDerivatives 44.0 


\title{
Biodegradable polyester thin films and coatings in the line of fire: The time of polyhydroxyalkanoate (PHA)?
}

\author{
Henri Vahabi ${ }^{\mathrm{a}, \mathrm{b},{ }^{*}}$, Elaheh Rohani Rad ${ }^{\mathrm{c}}$, Thibault Parpaite ${ }^{\mathrm{d}}$, Valérie Langlois ${ }^{\mathrm{e}}$, Mohammad Reza Saeb $^{\mathrm{a}, \mathrm{b},{ }^{*}}$ \\ ${ }^{a}$ Université de Lorraine, CentraleSupélec, LMOPS, F-57000 Metz, France \\ ${ }^{b}$ Laboratoire Matériaux Optiques, Photoniques et Systèmes, CentraleSupélec, Université Paris-Saclay, 57070, Metz, France \\ ${ }^{c}$ Faculty of Health and Medical Sciences, The University of Adelaide, SA, Adelaide, Australia \\ ${ }^{d}$ Precision Macromolecular Chemistry Group, Institut Charles Sadron, CNRS-UPR 22, 23 rue du Loess, 67034, Strasbourg Cedex 2, France \\ ${ }^{e}$ Institut de Chimie et des Matériaux Paris-Est, Université Paris Est, UMR 7182, CNRS, 2-8 rue Henri Dunant, 94320 Thiais, France
}

\section{Summary}

From sustainability standpoint, bio-based resins are of crucial importance nowadays rather than fossilbased resins, but the former has lower flame retardancy. Bio-based coatings are in their early stages; therefore, a long way must be gone to make them resistant against flame. Polylactic acid (PLA)-based biodegradable coatings have been in the core of attention, but one can rarely find reports on flame retardancy of bio-based thin films and coatings. Attention should also be paid to the fact that firstgeneration biodegradable polyesters, PLAs, are hooked on crop consumption. On the other hand, polyhydroxyalkanoates (PHAs) with more or less similar structure, but different physical properties arising from their lower glass transition temperature compared with PLAs, are known as the secondgeneration of bio-polyester. Overall, we highlight here that PHAs might a better candidate for thin film manufacturing thanks to their synthesis by microorganism. Though mass production of PHAs is not costeffective these days and their market just entered into the growth phase, we suggest study on flame retardancy of PHA-based resins, thin films, and coatings. This short communication deals with the current status and future ahead of PHA-based flame retardant thin films and coatings.

Keywords: Bio-based coating; Fire retardancy; Polyhydroxyalkanoate (PHA); sustainability

\footnotetext{
*Authors to whom correspondence should be addressed:

Dr. Henri Vahabi; E-mail: henri.vahabi@univ-lorraine.fr

Dr. Mohammad Reza Saeb; E-mail:mrsaeb2008@gmail.com
} 


\section{INTRODUCTION}

Bio-based and biodegradable polymers such as chitosan [1], agarose [2], gelatin [3] and silk [4] have received a considerable attention in recent years, even more than what an optimistic could hope, due to ever increasing sustainable development. Environmental threats and resource limitations are the main issues accompanied by the use of fuel-based polymers [5-9]. Such debates have aligned the developed countries in the need of replacement of unsustainable routes in manufacturing advanced materials and systems as well as developing modern technologies to draw a green horizon of opportunities upon material design [10-13]. Synthesis of bio-based and biodegradable resins still experiences early stages of development; therefore, a long road should be paved to make bio-based resins directed toward global plastic market [14-19]. Research on naturally driven, bioengineered, and synthetic biopolymers gained from bacteria, conventional biotechnology, and biomass has undergone an accelerating trend just in between 1993 and 2012 by ca. 35-fold and 15-fold rise in the number of scientific papers and patents, respectively [20-22]. Synthesis of polylactic acid (PLA) as the first-generation biodegradable polyester opened hope tracks beyond commercialization of bio-resins for widespread uses [23]. PLA known as the most promising bio-resin comes from fermentation via conventional chemistry followed by polymerization of lactic acid [24]. Undesirably, however, a large volume of corn, the main food supply in developing countries, must be utilized in the synthesis of PLA, which remains big challenge over future ahead of PLA production $[25,26]$. An elaborate analysis of patents unraveled that long-term research and development on PLA aligned it in the line of maturity, but its limited potential of commercialization was recognized for further PLA market progression [27].

Despite promising aspects of bio-resins for a sustainable future, they are highly flammable as well as they show poor mechanical properties; hence, they should be modified/reinforced with additives [28]. Pursuing instructions on the ban of usage of some halogenated flame retardants, substantial attempts were directed toward development of bio-based additives to meet low toxic product emission requirements [29-32]. Fire retardancy of bio-based resins filled with minerals, biofillers, biofibers, as well as bio-based composites composed of both bio-matrix and biofillers has been the focus of a wide variety of surveys over the past decade [33-38]. PLA- 
based flame retardant systems from metal oxide source were extensively studied, but the use of phosphorous-based and nanoclay flame retardant additives, alone or combinatorial, still remains in a long research road with a trace of hope in resolving poor mechanical properties of PLA composites[39].

The advent of polyhydroxyalkanoate (PHA) as second-generation fully biodegradable polyester resin through synthesis from a wide range of microorganisms and bacteria has eliminated the need for fermentation of crops [40-42]. This biogenic resin has just entered the market, but rapidly experienced growth period [43]. PHA family resins are appropriate candidates for energy storage and intracellular carbon purposes. They can be classified into short-chain length $\left(\mathrm{C}_{3}-\mathrm{C}_{5}\right)$ and medium-chain length $\left(\mathrm{C}_{6}-\mathrm{C}_{14}\right)$ groups with poly(3-hydroxybutyrate) (PHB) as the first widespread resin $[44,45]$. Thanks to their compatibility to blood and tissues and low permeability against $\mathrm{H}_{2} \mathrm{O}, \mathrm{CO}$, and $\mathrm{O}_{2}$, PHAs have been used in a wide variety of fields ranging from food packaging industry to tissue engineering (Figure 1) [46-49]. Nevertheless, high production cost and poor mechanical properties were recognized as major drawbacks that have limited large-scale application of PHA [50]. In this sense, modification of PHA by the aid of plasticizers, its blending with the second polymer, and its chemical modification with different functional groups/chains were examined[51, 52]. 


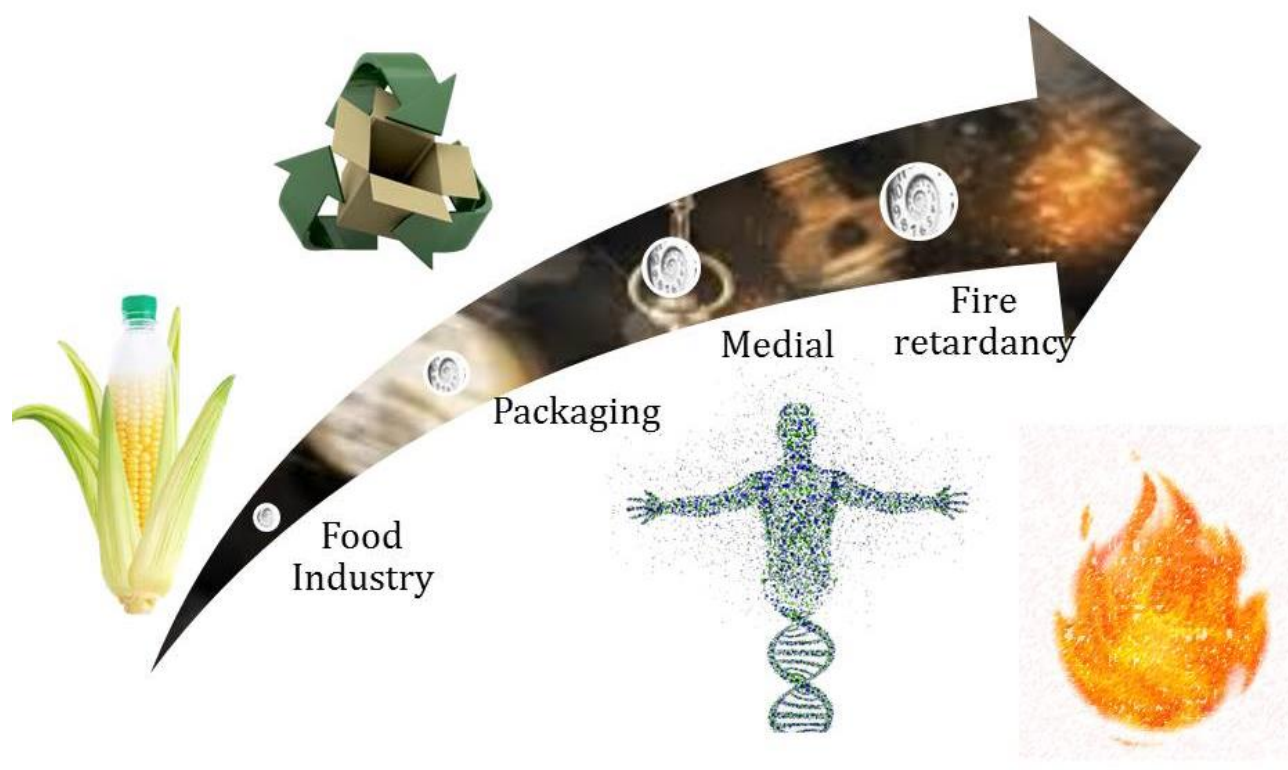

Fig. 1. Developments in application of biodegradable polyesters, PHA in the line of fire.

Bio-based thin films and coatings have opened new era of research for widespread uses. Fu et al. synthesized and fully characterized bio-based waterborne polyurethane dispersions starting from castor oil by the use of chain extender, and obtained good thermal and hydrophobic properties[53]. Turkenburg et al. developed highly thermos-reversible self-healing coatings by incorporation of high amounts of bio-based precursors and reported acceptable abrasive wear and solvent resistance together with mechanical properties [54]. There have also been some attempts to synthesis of bio-based UV-curable resins for applications in waterborne coatings [55-58] in the quest of adhesion, flexibility, mechanical and anti-corrosion properties. Biodegradable coatings based on waterborne polyester $[59,60]$ as well as vegetable oil-derived nanocomposite coatings were also investigated [60]. The open literature suggests that biobased polyurethane resins were quite often the subject of studies in this field $[60,61]$.

There are several reports on PLA-based coatings. Active PLA films used in packaging containing bergamot, rosemary, lemongrass or clove essential oils were developed by Qin et al., where acceptable antimicrobial and mechanical properties were obtained [62]. Elsewhere addition of equivalent weight of acrylic polyol and PLA ended in packaging films resistant against humidity 
and the cured films revealed good hydrolytic degradation resistance in humid media [63]. Durable hydrophobic PLA coatings obtained from pulsed plasma polymerization [64], fastformed microporous PLA coatings [65], nanostructured composite coatings based on PLA and amorphous magnesium phosphate with anti-corrosion and bioactivity characters [66], and PLAbased nanocomposite coatings from electron beam with substantial antibacterial features [67] were also subjects of research. There were also some works on the use of blends of PLA or PHB with other polymers, e.g. thin films and bio-coatings based on PHB and cellulose showing improved tensile properties [68]. Biodegradable smooth coatings based on polycarbonate and PLA [69] were among limited reports on the use of second-generation PHA coatings. It is worthy of note that the blend of PHA and PLA lacks miscibility; hence, chain extenders make possible formation of compatible bio-based coatings with acceptable thermal and mechanical properties thanks to intensified intermolecular entanglements [70, 71].

The quantity of research on flame retardancy of PLA thin films and coatings containing flame retardant additives is indeed limited. Solution casting PLA films containing phosphorous flame retardant were examined for thermal stability and flame retardancy performance in terms of the limiting oxygen index (LOI), UL-94, and themogravimetric analysis (TGA) [72]. There are some works on the individual or combined use of conventional flame retardants with nanoparticles in PLA thin films. Shi et al. used nanoparticles of metal-organic framework (MOF) in PLA solution film casting having thickness of ca. $140 \mu \mathrm{m}$ for electronic devices [73]. The LOI value for neat PLA film was ca. $20 \%$, which was indeed low. The neat sample failed in UL-94 test and continued to burning for about $21 \mathrm{~s}$, implying high flammability of PLA. The surprising point wat that by incorporation of just 0.2 wt.\% of MOF into PLA films the LOI value increased to $23.5 \%$, and nanocomposite sample burned in a very shorter time of ca. $16 \mathrm{~s}$. Increase of MOF content to 1 and $3 \mathrm{wt}$.\% in the PLA film caused rise in LOI to 24.5 and $26.0 \%$, respectively. In the same direction, burning times were decreased to 4.3 and 2.9 s. Film-stacking method was also used to obtain PLA films containing 10:1 ratio of polyphosphorous: montmorillonite (MMT), where self-extinguishing PLA films were achieved at 16 wt.\% flame retardant content [74]. Having met V-0 rating UL-94 as well as up to $50 \%$ decrease in the value of peak of Heat Release Rate (pHRR) in cone calorimetry measurements and the Total Heat Release (THR) were 
signatures of a superior fire retardancy performance. The combined use of a phosphinic acidcontained precursor and layered double hydroxide (LDH) [75] and a hybrid containing di(phenyl phosphate) (RDP), MOF, resorcinol, and graphene oxide (GO) [76] in PLA solution-casted films was successful in achieving good fire retardancy performance. Investigations also unraveled high potential of PLA nonwoven mats with intumescent features when ammonium polyphosphate (APP) was blended with lignin and starch carbohydrates [77].

In the light of above discussion, this short communication intends to place stress on the importance of research on flame retardancy of PHA-based family as potential era of survey in the field. Though kinetic study on thermal degradation of PHB was addressed in two reports, flame retardancy of neat PHA has never been reported. Except a work on the blend of PHB with poly(butylene adipate-co-terephthalate) (PBAT) filled with combination of nano-iron oxide and antimony oxide with emphasis being placed on superiority of additives $[78,79]$, no report is available in the literature on flame behavior of PHA-based systems. This is why we pictured here a potential framework for research on flame retardancy of PHA-based composites, looking at present from the future window. Figure $\mathbf{2}$ provides a comprehensive comparison of some physical and structural characteristics of PLA and PHA [80]. Although the density of PLA and PHA are the same, glass transition temperature $\left(T_{g}\right)$ of PLA is well above room temperature, notifying suitableness of PHA for usage in moderate temperature. PHA behaves like ductile materials at room temperature due to low $T_{g}$, however, its $T_{g}$ can be changed for lower or higher levels by incorporation of additives and plasticizers. Moreover, PHA is a semi-crystalline biodegradable polyester; while PLA possesses somehow an amorphous structure. Water permeability of PHA stands lower than PLA, due to the presence of crystalline domains, which offers PHA as a potential candidate for packaging industry. Thus, comparison between thermal stability and flame retardancy performances of PHA and PLA would be motivating. 
Density $\left(\mathrm{g} / \mathrm{cm}^{3}\right): 1.25$

Glass transition temp $\left({ }^{\circ} \mathrm{C}\right): \mathbf{5 8}$

Modulus at RT (MPa): 2000

Crystallinity (\%): 10

Water permeability $\left(\mathrm{g} / \mathrm{m}^{2}\right.$.day): 172

\section{?}

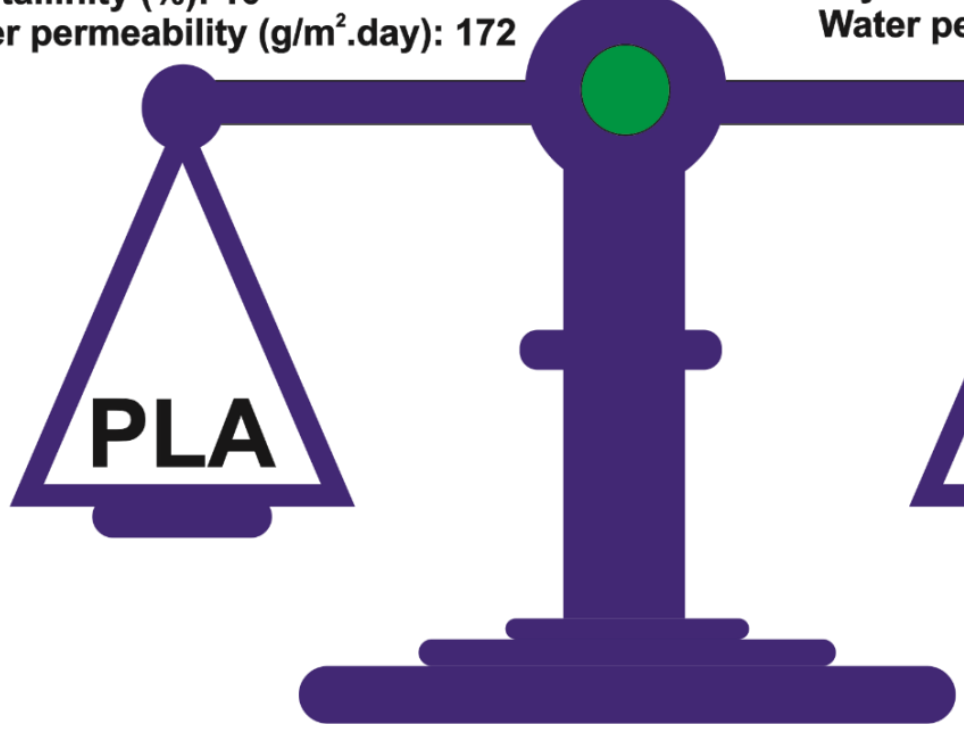

Figure 2: General comparison of final properties of PLA and PHA

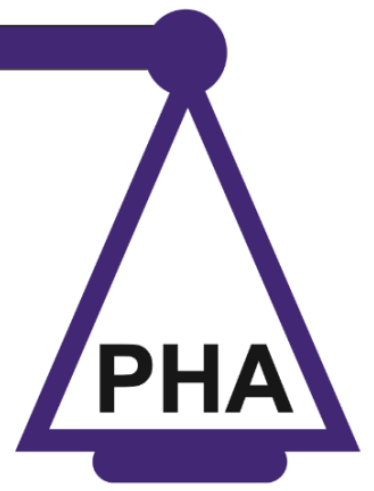

Density $\left(\mathrm{g} / \mathrm{cm}^{3}\right): 1.25$

Glass transition temp $\left({ }^{\circ} \mathrm{C}\right): 5$

Modulus at RT (MPa): 900

Crystallinity (\%): 50

Water permeability $\left(\mathrm{g} / \mathrm{m}^{2}\right.$.day): 21

\section{CONCLUSION}

Biodegradable polymers appeared as candidates for wide variety of fields thanks to their environmental-friendly and almost respectable properties. However, inadequate flame retardancy and mechanical strength of biopolymers have opened doors to substantial research in recent years to tackle their drawbacks. In the meanwhile, some promising outcomes have positioned them in the way commercialization. PLA belongs to the first generation of biodegradable polyesters, which is produced from food supply resources, mainly corns. However, substantial volume of corn is required in synthesis of PLA, which remains an unsolved problem in their large-scale production. Furthermore, PLA products suffer from very high flammability, along with insufficient mechanical properties-what suggests blending them with additives to reimburse their defects. These severe drawbacks highlights the need for synthesis of PHA as the second generation of fully biodegradable polyesters through microorganisms to 
eliminate the usage of corn. PHA has been found many potential applications in wide variety of fields thanks to biocompatibility, biodegradability, and low permeability against $\mathrm{H}_{2} \mathrm{O}, \mathrm{CO}$, and $\mathrm{O}_{2}$. Though researchers and technologists alike have addressed flame retardancy of PLA, no report is available on flame retardancy of PHA. This communication intends to underline the importance of research in this filed and seeks to encourage researchers working on flame retardancy of biobased polymers to take direction towards PHA.

\section{References}

[1] S. Mohebbi, M.N. Nezhad, P. Zarrintaj, S.H. Jafari, S.S. Gholizadeh, M.R. Saeb, M. Mozafari, Chitosan in biomedical engineering: a critical review, Current stem cell research \& therapy, 14 (2019) 93-116.

[2] P. Zarrintaj, S. Manouchehri, Z. Ahmadi, M.R. Saeb, A.M. Urbanska, D.L. Kaplan, M. Mozafari, Agarose-based biomaterials for tissue engineering, Carbohydrate polymers, 187 (2018) 66-84.

[3] P. Zarrintaj, A.M. Urbanska, S.S. Gholizadeh, V. Goodarzi, M.R. Saeb, M. Mozafari, A facile route to the synthesis of anilinic electroactive colloidal hydrogels for neural tissue engineering applications, Journal of colloid and interface science, 516 (2018) 57-66.

[4] M. Farokhi, F. Mottaghitalab, Y. Fatahi, M.R. Saeb, P. Zarrintaj, S.C. Kundu, A. Khademhosseini, Silk fibroin scaffolds for common cartilage injuries: possibilities for future clinical applications, European Polymer Journal, (2019).

[5] G. Papageorgiou, Thinking Green: Sustainable Polymers from Renewable Resources, in, Multidisciplinary Digital Publishing Institute, 2018.

[6] F. Laoutid, H. Vahabi, M. Shabanian, F. Aryanasab, P. Zarrintaj, M. Saeb, A new direction in design of bio-based flame retardants for poly (lactic acid), Fire and Materials, 42 (2018) 914-924.

[7] H. Vahabi, M.R. Saeb, K. Formela, J.-M.L. Cuesta, Flame retardant epoxy/halloysite nanotubes nanocomposite coatings: Exploring low-concentration threshold for flammability compared to expandable graphite as superior fire retardant, Progress in Organic Coatings, 119 (2018) 8-14.

[8] N. Omri, M.A. Oualha, H. Vahabi, N. Amdouni, M. Abderrabba, F. Laoutid, Promising effect of combining [60]Fullerene nanoparticles and calcium hydroxide on thermal stability and flammability of Poly(ethylene-co-vinyl acetate), Thermochimica Acta, 668 (2018) 73-79.

[9] H. Vahabi, S.M.R. Paran, M. Shabanian, L. Dumazert, R. Sonnier, E. Movahedifar, P. Zarrintaj, M.R. Saeb, Triple-faced polypropylene: Fire retardant, thermally stable, and antioxidative, Journal of Vinyl and Additive Technology, 0.

[10] V. Mittal, Renewable polymers: synthesis, processing, and technology, John Wiley \& Sons, 2011.

[11] C.K. Williams, M.A.J.P.r. Hillmyer, Polymers from renewable resources: a perspective for a special issue of polymer reviews, 48 (2008) 1-10.

[12] S. Ghiyasi, M.G. Sari, M. Shabanian, M. Hajibeygi, P. Zarrintaj, M. Rallini, L. Torre, D. Puglia, H. Vahabi, M. Jouyandeh, Hyperbranched poly (ethyleneimine) physically attached to silica nanoparticles to facilitate curing of epoxy nanocomposite coatings, Progress in Organic Coatings, 120 (2018) 100-109.

[13] M.G. Sari, H. Vahabi, X. Gabrion, P. Laheurte, P. Zarrintaj, K. Formela, M.R. Saeb, An attempt to mechanistically explain the viscoelastic behavior of transparent epoxy/starch-modified ZnO nanocomposite coatings, Progress in Organic Coatings, 119 (2018) 171-182. 
[14] S. Ma, X. Liu, Y. Jiang, Z. Tang, C. Zhang, J. Zhu, Bio-based epoxy resin from itaconic acid and its thermosets cured with anhydride and comonomers, Green Chemistry, 15 (2013) 245-254.

[15] R. Masoodi, R. El-Hajjar, K. Pillai, R. Sabo, Mechanical characterization of cellulose nanofiber and bio-based epoxy composite, Materials \& Design (1980-2015), 36 (2012) 570-576.

[16] M. Shibata, K. Nakai, Preparation and properties of biocomposites composed of bio-based epoxy resin, tannic acid, and microfibrillated cellulose, Journal of Polymer Science Part B: Polymer Physics, 48 (2010) 425-433.

[17] E.A. Baroncini, S. Kumar Yadav, G.R. Palmese, J.F. Stanzione III, Recent advances in bio-based epoxy resins and bio-based epoxy curing agents, Journal of Applied Polymer Science, 133 (2016).

[18] H. Nakajima, P. Dijkstra, K.J.P. Loos, The recent developments in biobased polymers toward general and engineering applications: Polymers that are upgraded from biodegradable polymers, analogous to petroleum-derived polymers, and newly developed, 9 (2017) 523.

[19] S. Manouchehri, B. Bagheri, S.H. Rad, M.N. Nezhad, Y.C. Kim, O.O. Park, M. Farokhi, M. Jouyandeh, M.R. Ganjali, M.K. Yazdi, Electroactive bio-epoxy incorporated chitosan-oligoaniline as an advanced hydrogel coating for neural interfaces, Progress in Organic Coatings, 131 (2019) 389-396.

[20] R.P. Babu, K. O'connor, R.J.P.i.B. Seeram, Current progress on bio-based polymers and their future trends, 2 (2013) 8.

[21] M.G. Sari, M.R. Saeb, M. Shabanian, M. Khaleghi, H. Vahabi, C. Vagner, P. Zarrintaj, R. Khalili, S.M.R. Paran, B. Ramezanzadeh, Epoxy/starch-modified nano-zinc oxide transparent nanocomposite coatings: a showcase of superior curing behavior, Progress in Organic Coatings, 115 (2018) 143-150.

[22] E. Yarahmadi, K. Didehban, M.G. Sari, M.R. Saeb, M. Shabanian, F. Aryanasab, P. Zarrintaj, S.M.R. Paran, M. Mozafari, M. Rallini, Development and curing potential of epoxy/starch-functionalized graphene oxide nanocomposite coatings, Progress in Organic Coatings, 119 (2018) 194-202.

[23] M. Wang, Y. Wu, Y.-D. Li, J.-B.J.P.R. Zeng, Progress in toughening poly (lactic acid) with renewable polymers, 57 (2017) 557-593.

[24] H. Vahabi, M. Shabanian, F. Aryanasab, F. Laoutid, S. Benali, M.R. Saeb, F. Seidi, B.K. Kandola, Three in one: $\beta$-cyclodextrin, nanohydroxyapatite, and a nitrogen-rich polymer integrated into a new flame retardant for poly (lactic acid), Fire and Materials, 42 (2018) 593-602.

[25] T.A. Hottle, M.M. Bilec, A.E.J.P.D. Landis, Stability, Sustainability assessments of bio-based polymers, 98 (2013) 1898-1907.

[26] A.E.J.P.s. Landis, structures, properties, processing,, applications, Cradle to gate environmental footprint and life cycle assessment of poly (lactic acid), (2010) 431-441.

[27] D. Elvers, C.H. Song, A. Steinbüchel, J.J.P.R. Leker, Technology trends in biodegradable polymers: evidence from patent analysis, 56 (2016) 584-606.

[28] L. Costes, F. Laoutid, S. Brohez, P. Dubois, Bio-based flame retardants: When nature meets fire protection, Materials Science and Engineering: R: Reports, 117 (2017) 1-25.

[29] K.S.J.E.h.p. Betts, New thinking on flame retardants, 116 (2008) A210.

[30] H. Vahabi, M. Jouyandeh, M. Cochez, R. Khalili, C. Vagner, M. Ferriol, E. Movahedifar, B. Ramezanzadeh, M. Rostami, Z. Ranjbar, Short-lasting fire in partially and completely cured epoxy coatings containing expandable graphite and halloysite nanotube additives, Progress in Organic Coatings, 123 (2018) 160-167.

[31] H. Vahabi, B.K. Kandola, M.R. Saeb, Flame Retardancy Index for Thermoplastic Composites, Polymers, 11 (2019) 407.

[32] M. Hajibeygi, M. Maleki, M. Shabanian, F. Ducos, H. Vahabi, New polyvinyl chloride (PVC) nanocomposite consisting of aromatic polyamide and chitosan modified $\mathrm{ZnO}$ nanoparticles with enhanced thermal stability, low heat release rate and improved mechanical properties, Applied Surface Science, 439 (2018) 1163-1179. 
[33] G. Marosi, B. Szolnoki, K. Bocz, A. Toldy, Fire-retardant recyclable and biobased polymer composites, in: Novel Fire Retardant Polymers and Composite Materials, Elsevier, 2017, pp. 117-146.

[34] L. Costes, F. Laoutid, S. Brohez, P.J.M.S. Dubois, E.R. Reports, Bio-based flame retardants: When nature meets fire protection, 117 (2017) 1-25.

[35] R. Sonnier, A. Taguet, L. Ferry, J.-M. Lopez-Cuesta, Towards Bio-based Flame Retardant Polymers, Springer, 2018.

[36] R. Sonnier, A. Taguet, L. Ferry, J.-M. Lopez-Cuesta, Biobased Flame Retardants, in: Towards Biobased Flame Retardant Polymers, Springer, 2018, pp. 33-72.

[37] P. Zarrintaj, M.K. Yazdi, H. Vahabi, P.N. Moghadam, M.R. Saeb, Towards advanced flame retardant organic coatings: Expecting a new function from polyaniline, Progress in Organic Coatings, 130 (2019) 144-148.

[38] M. Sadeghi-Kiakhani, S. Khamseh, A. Rafie, S.M.F. Tekieh, P. Zarrintaj, M.R. Saeb, Thermally stable antibacterial wool fabrics surface-decorated by TiON and TiON/Cu thin films, Surface Innovations, 6 (2018) 258-265.

[39] B. Tawiah, B. Yu, B.J.P. Fei, Advances in Flame Retardant Poly (Lactic Acid), 10 (2018) 876.

[40] M. Koller, Advances in Polyhydroxyalkanoate (PHA) Production, in, Multidisciplinary Digital Publishing Institute, 2017.

[41] L. Cavaillé, M. Albuquerque, E. Grousseau, A.-S. Lepeuple, J.-L. Uribelarrea, G. Hernandez-Raquet, E.J.B.t. Paul, Understanding of polyhydroxybutyrate production under carbon and phosphorus-limited growth conditions in non-axenic continuous culture, 201 (2016) 65-73.

[42] A.A. Pantazaki, M.G. Tambaka, V. Langlois, P. Guerin, D.A.J.M. Kyriakidis, c. biochemistry, Polyhydroxyalkanoate (PHA) biosynthesis in Thermus thermophilus: purification and biochemical properties of PHA synthase, 254 (2003) 173-183.

[43] E. Bugnicourt, P. Cinelli, A. Lazzeri, V.A. Alvarez, Polyhydroxyalkanoate (PHA): Review of synthesis, characteristics, processing and potential applications in packaging, (2014).

[44] E.A.J.B.r. Dawes, Polyhydroxybutyrate: an intriguing biopolymer, 8 (1988) 537-547.

[45] M. Avella, E. Martuscelli, M.J.J.o.M.S. Raimo, Review Properties of blends and composites based on poly (3-hydroxy) butyrate (PHB) and poly (3-hydroxybutyrate-hydroxyvalerate)(PHBV) copolymers, 35 (2000) 523-545.

[46] B.S. Thorat Gadgil, N. Killi, G.V.N. Rathna, Polyhydroxyalkanoates as biomaterials, MedChemComm, 8 (2017) 1774-1787.

[47] P. Zarrintaj, A.S. Moghaddam, S. Manouchehri, Z. Atoufi, A. Amiri, M.A. Amirkhani, M.A. Nilforoushzadeh, M.R. Saeb, M.R. Hamblin, M. Mozafari, Can regenerative medicine and nanotechnology combine to heal wounds? The search for the ideal wound dressing, Nanomedicine, 12 (2017) 2403-2422.

[48] T. Tariverdian, P. Zarintaj, P.B. Milan, M.R. Saeb, S. Kargozar, F. Sefat, A. Samadikuchaksaraei, M. Mozafari, Nanoengineered biomaterials for kidney regeneration, in: Nanoengineered Biomaterials for Regenerative Medicine, Elsevier, 2019, pp. 325-344.

[49] M.A. Nilforoushzadeh, M. Zare, P. Zarrintaj, E. Alizadeh, E. Taghiabadi, M. Heidari-Kharaji, M.A. Amirkhani, M.R. Saeb, M. Mozafari, Engineering the niche for hair regeneration-a critical review, Nanomedicine: Nanotechnology, Biology and Medicine, (2018).

[50] C. Kourmentza, J. Plácido, N. Venetsaneas, A. Burniol-Figols, C. Varrone, H.N. Gavala, M.A.M. Reis, Recent Advances and Challenges towards Sustainable Polyhydroxyalkanoate (PHA) Production, 4 (2017) 55.

[51] Z. Li, J. Yang, X.J.J.N.A.M. Loh, Polyhydroxyalkanoates: opening doors for a sustainable future, 8 (2016) e265.

[52] K. Khosravi-Darani, D.J.C. Bucci, b.e. quarterly, Application of poly (hydroxyalkanoate) in food packaging: Improvements by nanotechnology, 29 (2015) 275-285. 
[53] C. Fu, Z. Zheng, Z. Yang, Y. Chen, L. Shen, A fully bio-based waterborne polyurethane dispersion from vegetable oils: From synthesis of precursors by thiol-ene reaction to study of final material, Progress in Organic Coatings, 77 (2014) 53-60.

[54] D.H. Turkenburg, Y. Durant, H.R. Fischer, Bio-based self-healing coatings based on thermoreversible Diels-Alder reaction, Progress in Organic Coatings, 111 (2017) 38-46.

[55] J. Dai, S. Ma, X. Liu, L. Han, Y. Wu, X. Dai, J. Zhu, Synthesis of bio-based unsaturated polyester resins and their application in waterborne UV-curable coatings, Progress in Organic Coatings, 78 (2015) 49-54.

[56] J. Dai, S. Ma, Y. Wu, J. Zhu, X. Liu, High bio-based content waterborne UV-curable coatings with excellent adhesion and flexibility, Progress in Organic Coatings, 87 (2015) 197-203.

[57] A.Z. Yu, J.M. Sahouani, D.C. Webster, Highly functional methacrylated bio-based resins for UVcurable coatings, Progress in Organic Coatings, 122 (2018) 219-228.

[58] F. Millet, R. Auvergne, S. Caillol, G. David, A. Manseri, N. Pébère, Improvement of corrosion protection of steel by incorporation of a new phosphonated fatty acid in a phosphorus-containing polymer coating obtained by UV curing, Progress in Organic Coatings, 77 (2014) 285-291.

[59] D.K. Geeti, K. Niranjan, Environmentally benign bio-based waterborne polyesters: Synthesis, thermal- and bio-degradation studies, Progress in Organic Coatings, 127 (2019) 419-428.

[60] M. Nejad, P. Cooper, V. Landry, P. Blanchet, A. Koubaa, Studying dispersion quality of nanoparticles into a bio-based coating, Progress in Organic Coatings, 89 (2015) 246-251.

[61] A. Noreen, K.M. Zia, M. Zuber, S. Tabasum, A.F. Zahoor, Bio-based polyurethane: An efficient and environment friendly coating systems: A review, Progress in Organic Coatings, 91 (2016) 25-32.

[62] Y. Qin, W. Li, D. Liu, M. Yuan, L. Li, Development of active packaging film made from poly (lactic acid) incorporated essential oil, Progress in Organic Coatings, 103 (2017) 76-82.

[63] K. Morita, H. Yamashita, N. Yabuuchi, M. Ishii, M. Arimoto, K. Ishimoto, H. Ohara, S. Kobayashi, Antihydrolysis performance of cured coating films of acrylic polyols with pendant poly(lactic acid)s, Progress in Organic Coatings, 78 (2015) 183-187.

[64] A. Khoddami, O. Avinc, S. Mallakpour, A novel durable hydrophobic surface coating of poly(lactic acid) fabric by pulsed plasma polymerization, Progress in Organic Coatings, 67 (2010) 311-316.

[65] O.C. Onder, M.A. Nazeer, E. Yilgör, I. Yilgör, Spontaneous formation of microporous poly(lactic acid) coatings, Progress in Organic Coatings, 125 (2018) 249-256.

[66] Y. Ren, E. Babaie, S.B. Bhaduri, Nanostructured amorphous magnesium phosphate/poly (lactic acid) composite coating for enhanced corrosion resistance and bioactivity of biodegradable AZ31 magnesium alloy, Progress in Organic Coatings, 118 (2018) 1-8.

[67] C. He, Q. Chen, M.A. Yarmolenko, A.A. Rogachev, D.G. Piliptsou, X. Jiang, A.V. Rogachev, Structure and antibacterial activity of PLA-based biodegradable nanocomposite coatings by electron beam deposition from active gas phase, Progress in Organic Coatings, 123 (2018) 282-291.

[68] V.P. Cyras, C.M. Soledad, V. Analía, Biocomposites based on renewable resource: Acetylated and non acetylated cellulose cardboard coated with polyhydroxybutyrate, Polymer, 50 (2009) 6274-6280.

[69] Y. Chen, Y. Song, S. Zhang, J. Li, C. Zhao, X. Zhang, Interaction between a high purity magnesium surface and PCL and PLA coatings during dynamic degradation, Biomedical Materials, 6 (2011) 025005.

[70] T.P. Dawin, Z. Ahmadi, F.A. Taromi, Bio-based solution-cast blend films based on polylactic acid and polyhydroxybutyrate: Influence of pyromellitic dianhydride as chain extender on the morphology, dispersibility, and crystallinity, Progress in Organic Coatings, 119 (2018) 23-30.

[71] T.P. Dawin, Z. Ahmadi, F.A. Taromi, Biocompatible PLA/PHB coatings obtained from controlled solid state polymerization, Progress in Organic Coatings, 132 (2019) 41-49.

[72] M.-J. Sim, S.-H. Cha, Efficient polymeric phosphorus flame retardant: flame retardancy, thermal property, and physical property on polylactide, Polymer Bulletin, (2018) 1-17. 
[73] X. Shi, X. Dai, Y. Cao, J. Li, C. Huo, X. Wang, Degradable Poly (lactic acid)/metal-organic framework nanocomposites exhibiting good mechanical, flame retardant, and dielectric properties for the fabrication of disposable electronics, Industrial \& Engineering Chemistry Research, 56 (2017) 3887-3894. [74] K. Bocz, M. Domonkos, T. Igricz, Á. Kmetty, T. Bárány, G. Marosi, Flame retarded self-reinforced poly(lactic acid) composites of outstanding impact resistance, Composites Part A: Applied Science and Manufacturing, 70 (2015) 27-34.

[75] P. Ding, B. Kang, J. Zhang, J. Yang, N. Song, S. Tang, L. Shi, Phosphorus-containing flame retardant modified layered double hydroxides and their applications on polylactide film with good transparency, Journal of Colloid and Interface Science, 440 (2015) 46-52.

[76] M. Zhang, Y. Gao, Y. Zhan, X. Ding, M. Wang, X. Wang, Preparing the Degradable, Flame-Retardant and Low Dielectric Constant Nanocomposites for Flexible and Miniaturized Electronics with Poly (lactic acid), Nano ZIF-8@ GO and Resorcinol Di (phenyl phosphate), Materials, 11 (2018) 1756.

[77] C. Reti, M. Casetta, S. Duquesne, R. Delobel, J. Soulestin, S. Bourbigot, Intumescent biobasedpolylactide films to flame retard nonwovens, Journal of Engineered Fibers and Fabrics, 4 (2009) 155892500900400206.

[78] E. Gallo, B. Schartel, D. Acierno, P.J.E.P.J. Russo, Flame retardant biocomposites: synergism between phosphinate and nanometric metal oxides, 47 (2011) 1390-1401.

[79] H. Ariffin, H. Nishida, Y. Shirai, M.A. Hassan, Determination of multiple thermal degradation mechanisms of poly(3-hydroxybutyrate), Polymer Degradation and Stability, 93 (2008) 1433-1439.

[80] I. Chodak, Polyhydroxyalkanoates: origin, properties and applications, in: Monomers, polymers and composites from renewable resources, Elsevier, 2008, pp. 451-477. 